\title{
SUSTAINABLE DEVELOPMENT AND MANAGEMENT IN CONSUMER ELECTRONICS USING SOFT COMPUTATION
}

\author{
Dr. Haoxiang Wang, \\ Department of Electrical and Computer Engineering, Cornell University, \\ Ithaca, USA. \\ Email id: wanghaoxiang1102@hotmail.com
}

\begin{abstract}
Combination of Green supply chain management, Green product deletion decision and green cradle-to-cradle performance evaluation with Adaptive-Neuro-Fuzzy Inference System (ANFIS) to create a green system. Several factors like design process, client specification, computational intelligence and soft computing are analysed and emphasis is given on solving problems of real domain. In this paper, the consumer electronics and smart systems that produce nonlinear outputs are considered. ANFIS is used for handling these nonlinear outputs and offer sustainable development and management. This system offers decision making considering multiple objectives and optimizing multiple outputs. The system also provides efficient control performance and faster data transfer.
\end{abstract}

Keywords: Soft Computation, Consumer Electronics, Neural Network, ANFIS, Machine Learning

\section{INTRODUCTION}

Electronic devices like computer, television, smartphones, digital camera, microwave, air conditioner, home security and several others. With the invention of IoT and several other innovative technologies, automation of all these devices is made possible. The industry of consumer electronics has several risks due to uncertainty of demand and short lifecycle of products. Computational intelligence is mainly of three forms - natural computing, quantum computing and soft computing. Resolving complex computational glitches is done by providing inaccurate but functional solutions with estimated calculations by means of soft computing. It allows resolving of issues that are tedious to be solved with hardware or are unsolvable. Unlike traditional computing models, soft computing has tolerance of estimation, inaccuracy, improbability and partial certainties. These features helps researchers to solve certain issues that cannot be addressed by the traditional computing methods.

The simple fuzzy control system structure is composed of four components namely- De-fuzzification interface, inference engine, fuzzification interface and knowledge base. The information of the controller is stored in the knowledge base. It contains the fuzzy control database that describes concepts, terms and facts of the objects 
and rule base that comprises of the information based on which the control actions on the objects can be inferred. Adaptive Network Based Fuzzy Inference System, also called as Adaptive-Neuro-Fuzzy Inference System (ANFIS) is a neuro-fuzzy method. The method combines fuzzy inference system with neural networks to form a hybrid model. The major ANFIS models available are Tsukamoto and Sugeno fuzzy models. Several fuzzy ifthen rules are presented in this algorithm with appropriate membership functions leading to the generation of the fuzzy inference system (FIS).

In this paper, ANFIS is used for building an intelligent and adaptive system using the sensors applied in consumer electronic goods. It allows sustainable development and management of these devices by allowing them to make dynamic decisions when used. Close security analysis feature of the system ensures safety while using the system over the internet. The rest of the paper is organized as follows- Section 2 studies the existing models of soft computing and ANFIS systems that are available, section 3 proposes the methodology of developing and managing the consumer electronics using soft computing, section 4 provides the output results and section 5 discusses the conclusion and future work of the system.

\section{EXISTING LITERATURE}

Several criteria such as environmental management system, reduction of generation of hazardous materials during production, green production, management support, internal green production plans, green certifications, green design, life cycle assessment, green purchasing capabilities, service quality, supplier flexibility, conformance quality, green technology capabilities, supplier relationship, supplier profitability and reliability of delivery form the basis of the framework as represented in the hierarchical structure as represented by Ming-Lang Tseng in [1]. The paper presented a green supply chain management criteria (GSCM) along with Fuzzy Set Theory and Grey Theory to reduce pollution 0-pand its associated impacts on the environment.

Ming-Lang et al [2] performed research in corporate-decision making models to address production and consumption methods for making decisions using soft computing. Chunguang et al [3] proposed an approach for evaluation of green product deletion decision with ecologically sustainable manufacturing and consumption environs. Promotion, placement, pricing and production are the major aspects of marketing as discussed by Salman et al in [5]. Handling of fuzziness and non-linearity is done in case of designing of new products while demonstrating consumer gratification affiliation. For this purpose, in fuzzy environments, ANFIS is used.

In Ref. [6], Chun-Wei et al proposed "A cradle-to-cradle analysis in the toner cartridge supply chain using fuzzy recycling production approach". The usage of reprocessed merchandises in manufacturing and logistic industries is becoming more common day by day. The paper uses a complete assessment model using fuzzy logic for the $\mathrm{C} 2 \mathrm{C}$ performance estimation based on revenue due to sales, expenses of waste disposal, shipping, packing, 
testing, assembly, recovery and so on. Yan-Ling et al [7] presented a system to improve the supply chain flexibility and responsiveness of the users of supply chain using multi-agent system.

Joanna Berzowska, in her article [8] has reviewed the application of soft computation in electronic textiles. These smart fabrics are packed with features like thermo-chromic pigments, flexible sensors, electronic ink, networking and communication, conductive yarns and so on. The tradition of electronics as well as textiles is merged to produce soft circuits that can sense information and transfer data and power. Dr.Sanjay Bhushan in [9] presented a "Feed Forward Enabled Interface of Artificial Neural Network to System Dynamics Modeling for Developing Experiential Expert System for Decentralized Marketing Logistics”

Gang Feng [10] analysed the existing fuzzy dynamic model, neuro-fuzzy model, adaptive fuzzy model, Takagi-Sugeno fuzzy model and other model based control systems. Fateme Zare Baghiabad et al [11] introduced “A Three- Stage Algorithm for Software Cost and Time Estimation in Fuzzy Environment”. The paper used triangular fuzzy numbers to assert ambiguity in cost of task, duration of task, beginning time, ending time, progression and recurrence of every production step. This system is compared with Constructive Cost Model (COCOMO) that is used for calculation of cost in huge software systems.

Miguel-Angel et al [13] proposed a model for "Software Cost Estimation with Fuzzy Inputs: Fuzzy Modelling and Aggregation of Cost Drivers". The system uses Application Experience (AEXP) and Required Reliability (RELY) processes to quote COCOMO cost drivers. Boris Izyumov et al [14] presented the analysis of regression in fuzzy data using software tools. When the source information has huge uncertainties, it can be solved by modelling the nonlinear function with a single variable quantity.

\section{PROPOSED WORK}

While developing the soft computing system with ANFIS, it is essential to choose the suitable design solution. Through the different levels of design process, the solution will be refined and developed. The factors considered in this process includes compliance of government protocols, transportability, cost, assemblage, simplicity of fabrication, manufacturing considerations and safety. 

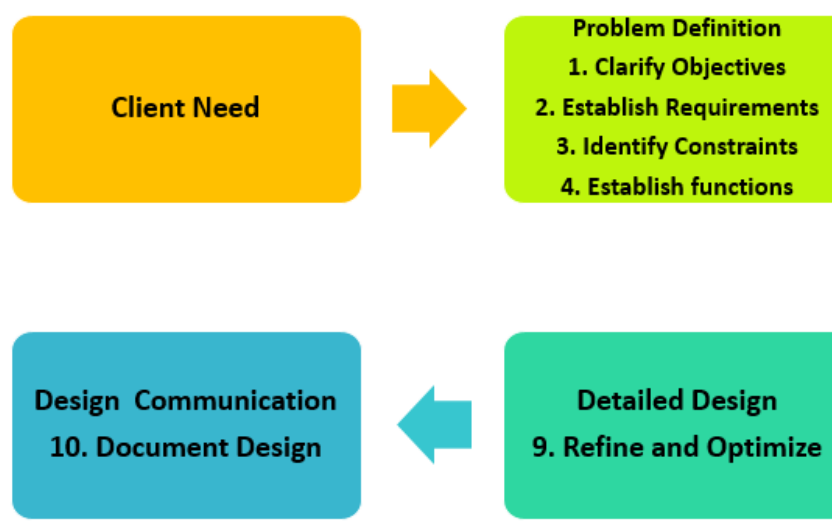

\section{Conceptual Design \\ 5. Establish \\ Specifications \\ 6. Generate alternatives}

4. Establish functions

Preliminary Design

7. Analyze design

8. Test and Evaluate

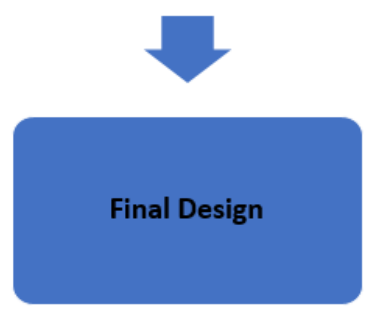

Figure 1: Typical design model

Figure 1 represents the typical design model with all the features that are to be taken into consideration while developing the model from the client needs to the final design. It undergoes 5 stages of design from problem identification to simulation model generation i.e. planning to execution. The life cycle of products, margin and other details are also analysed along with the time cost and threshold value of the sensor data. Figure 2 represents the problem based learning environment where the entire system is categorised into 6 models. It allows developing of the system with least support design. 


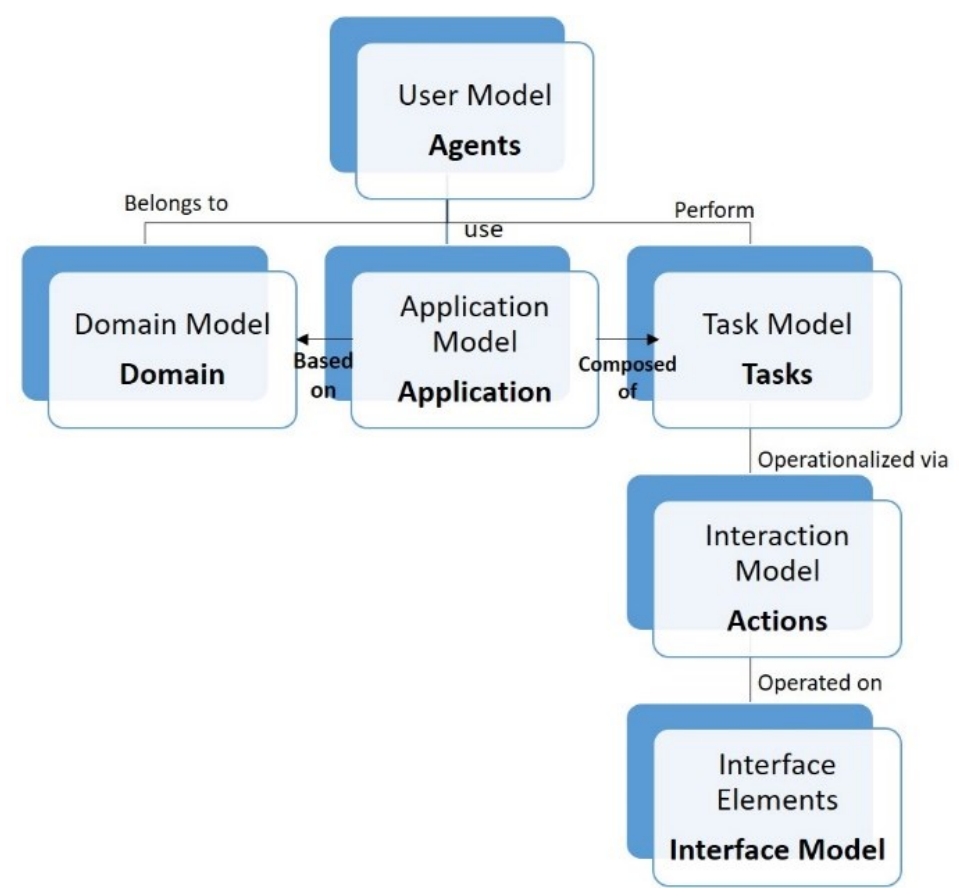

Figure 2: Problem based learning environments

The system is provided with six inputs. Diverse data collection is done via multiple sensors. Calculation of threshold value is done by ANFIS inference module with all inputs from similar sensors. Further, the overall threshold value is also calculated with the obtained six values. Using these threshold values, the management of the electronic devices are done offering improved efficiency in reliability and power. The decision making procedure mainly depends on the calculated threshold values. We can produce multiple outcomes based on these values using multiple ANFIS technology. While dealing with multiple outputs, it is essential to carefully model and optimize the process.

\section{RESULT}

The configuration of consumer electronics is done by connecting the outputs from sensor nodes to the server. Factors like temperature, frequency, motion, sound, video, light, pressure and so on can be captured by the sensors. Training and testing datasets are categorized based on the inputs. The impact of these inputs are assessed and sensitivity analysis is performed. This model effectively handles nonlinear associations like fuzziness and complexity between the development and management of the electronic devices.

The design practices, development factors, technology and tools, knowledge base are discussed for meaningful collaboration and creation of efficient framework. Table 1 gives the experiment results of analysis of 
Journal of Soft Computing Paradigm (JSCP) (2019)

Vol.01/ No. 01

Pages: 49-56

https://irojournals.com/jscp/

DOI: $\underline{\text { https://doi.org/10.36548/jscp.2019.1.006 }}$

the variables, sensors, experiments, time, and threshold values. The threshold values are in the 10 bit range of values from 0 to 1023 .

Table 1: Computational analysis of response time and threshold value based on independent variables

\begin{tabular}{|c|c|c|c|}
\hline Experiment Count & Independent Variable Count & $\begin{array}{c}\text { Random search duration } \\
\text { in sec. }\end{array}$ & $\begin{array}{c}\text { Average threshold } \\
\text { value }\end{array}$ \\
\hline 14 & 6 & 2.13 & 511 \\
\hline 34 & 5 & 1.59 & 482 \\
\hline 52 & 4 & 1.42 & 436 \\
\hline 64 & 3 & 1.23 & 375 \\
\hline 72 & 2 & 1.02 & 349 \\
\hline 86 & 1 & 0.56 & 295 \\
\hline
\end{tabular}

The analysis of these values is represented in the graphs as shown in figure 3 . The average threshold and average time duration required for the response in consumer electronic devices.

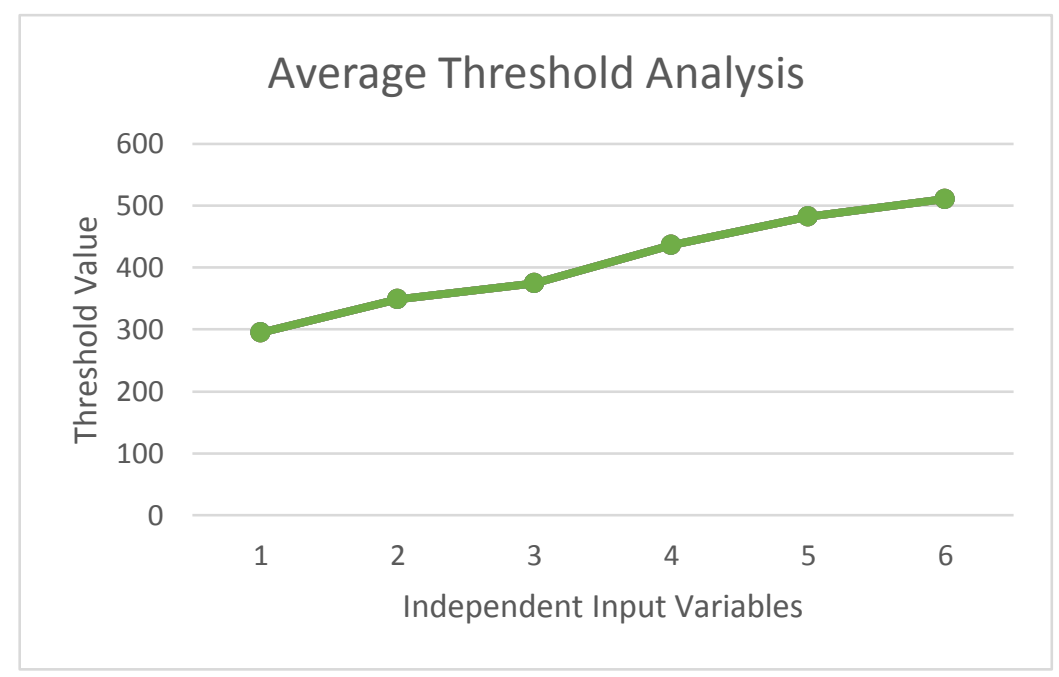

(a) 


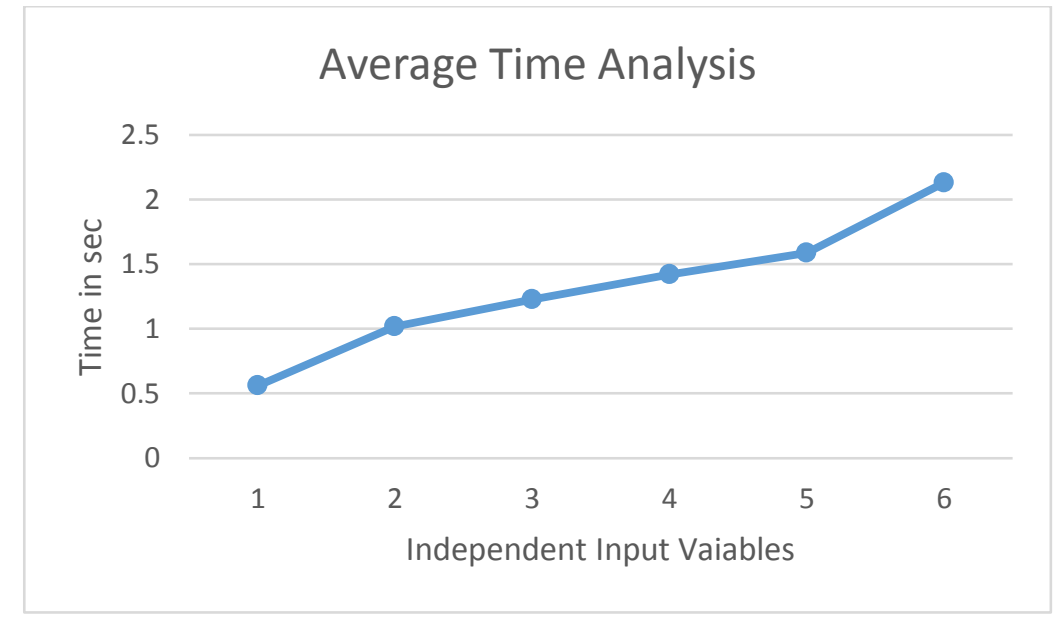

(b)

Figure 3: Analysis of Average (a) Threshold Value and (b) Response Time

\section{CONCLUSION AND FUTURE SCOPE}

Soft computing provides optimal solution to issues based on computational intelligence. This paper provides a system for developing and managing consumer electronic devices and goods using ANFIS. The paper also focuses on overcoming the problems while dealing with real time data such as noise, inconsistency and incompleteness. Lack of complete information leads to these problems. Soft computing can offer inaccurate but usable solutions with this data. These solutions help in management of the consumer electronic devices.

Future work in this will be focused on prototype development of this system and inclusion of more data analytic techniques. The analysis of customer satisfaction and allowing the development of improved products can also be added with this system to make a more complete system.

\section{References}

[1] Tseng, Ming-Lang. "Green supply chain management with linguistic preferences and incomplete information." Applied Soft Computing 11, no. 8 (2011): 4894-4903.

[2] Tseng, Ming-Lang, Qinghua Zhu, Joseph Sarkis, and Anthony SF Chiu. "Responsible consumption and production (RCP) in corporate decision-making models using soft computation." Industrial Management \& Data Systems 118, no. 2 (2018): 322-329. 
[3] Bai, Chunguang, Purvi Shah, Qingyun Zhu, and Joseph Sarkis. "Green product deletion decisions: An integrated sustainable production and consumption approach." Industrial Management \& Data Systems 118, no. 2 (2018): 349-389.

[4] Vakili, Masoud, Saeed-Reza Sabbagh-Yazdi, Koosha Kalhor, and Soheila Khosrojerdi. "Using artificial neural networks for prediction of global solar radiation in Tehran considering particulate matter air pollution." Energy Procedia 74 (2015): 1205-1212.

[5] Nazari-Shirkouhi, Salman, Abbas Keramati, and Kamran Rezaie. "Improvement of customers' satisfaction with new product design using an adaptive neuro-fuzzy inference systems approach." Neural Computing and Applications 23, no. 1 (2013): 333-343.

[6] Lin, Chun-Wei, Shiou-Yun Jeng, Ming-Lang Tseng, and Raymond Tan. "A cradle-to-cradle analysis in the toner cartridge supply chain using fuzzy recycling production approach." Management of Environmental Quality: An International Journal 30, no. 2 (2019): 329-345.

[7] Wang, Yan-Ling, Su-Wen Ye, and Guo-Qing Yan. "Multi-agent system developed for the logistics supply chain coordination and risk management." In 2010 International Conference on E-Business and EGovernment, pp. 3243-3246. IEEE, 2010.

[8] Berzowska, Joanna. "Electronic textiles: Wearable computers, reactive fashion, and soft computation." Textile 3, no. 1 (2005): 58-75.

[9] Bhushan, Sanjay. "Feed Forward Enabled Interface of Artificial Neural Network to System Dynamics Modeling for Developing Experiential Expert System for Decentralized Marketing Logistics." Indian Journal of Marketing, Forthcoming (2009).

[10] Feng, Gang. "A survey on analysis and design of model-based fuzzy control systems." IEEE Transactions on Fuzzy systems 14, no. 5 (2006): 676-697.

[11] Kovalnogova, Julia N., Oksana U. Yuldasheva, and Evgeny A. Kachagin. "Research of consumer behavior in the market of pharmaceutical cosmetics using fuzzy modeling." In AIP Conference Proceedings, vol. 2040, no. 1, p. 150011. AIP Publishing, 2018.

[12] Zarebaghiabad, Fateme, and Zare Hassan Khademi. "A three-stage algorithm for software cost and time estimation in fuzzy environment." (2015): 193-211.

[13] García-Bariocanal, E. L. E. N. A. "Software Cost Estimatюn with Fuzzy Inputs: Fuzzy Modelling and Aggregatin of Cost Drivers."

[14] Izyumov, Boris, Eleonora Kalinina, and Michael Wagenknecht. "Software tools for regression analysis of fuzzy data." In Proceedings of 9th Zittau Fuzzy Colloquium, pp. 221-229. 2001.

[15] Iraji, Mohammad Saber. "Fuzzy Agent Oriented Software Effort Estimate with COCOMO." International Journal of Intelligent Systems and Applications 7, no. 8 (2015): 18.

[16] RESOLUTION, LOW. "2Electronic Textiles: Wearable Computers, Reactive Fashion, and Soft Computation." (2005).

[17] Attarzadeh, Iman, and Siew H. Ow. "A novel algorithmic cost estimation model based on soft computing technique." Journal of Computer Science 6, no. 2 (2010): 117. 
Journal of Soft Computing Paradigm (JSCP) (2019)

Vol.01/ No. 01

Pages: 49-56

https://irojournals.com/jscp/

DOI: https://doi.org/10.36548/jscp.2019.1.006

[18] Wang, Yan-Ling. "Flexible and responsive multi-agent based logistics coordination management." In 2010 2nd IEEE International Conference on Information Management and Engineering, pp. 43-47. IEEE, 2010.

[19] Mitra, Sushmita, and Yoichi Hayashi. "Neuro-fuzzy rule generation: survey in soft computing framework." IEEE transactions on neural networks 11, no. 3 (2000): 748-768.

[20] Jyothirmai, Pondi, Jennifer S. Raj, and S. Smys. "Secured self-organizing network architecture in wireless personal networks.” Wireless Personal Communications 96, no. 4 (2017): 5603-5620.

[21] Azadi, S. H., HR Rezaei Nedamani, and R. Kazemi. "Automatic Parking of an Articulated Vehicle Using ANFIS." Global Journal of Science, Engineering and Technology (ISSN: 2322-2441) (2013): 93-104.

[22] Mon, Yi-Jen, Chih-Min Lin, and Imre J. Rudas. "ANFIS-based wireless sensor network (WSN) applications for air conditioner control." Acta Polytechnica Hungarica 10, no. 3 (2013): 5-16.

[23] Sang-Hyun, Lee, Jeong-Gi Lee, and Moon Kyung-Il. "Smart home security system using multiple ANFIS." Int. J. Smart Home 7, no. 3 (2013): 121-132.

[24] Kiyak, İsmail, Vedat Topuz, and Bülent Oral. "Modeling of dimmable High Power LED illumination distribution using ANFIS on the isolated area." Expert Systems with Applications 38, no. 9 (2011): 1184311848. 